Some of the most effective modern drugs are complex biological molecules. As their patents expire, drug developers are fashioning copycat versions that could make such therapies cheaper and more broadly available. By Michael Eisenstein; infographic by Mohamed Ashour.

\section{BIG BUSINESS}

Biological drugs (biologics) pharmaceutical drugs that are based on biological molecules such as proteins - accounted for almost one-quarter of drug spending worldwide in 2015. That fraction is set to continue to grow in the years ahead.

Most biologics that achieve huge sales are targeted at common medical conditions. Drugs that tackle various types of cancer, diabetes and specific immune disorders represented more than half of global spending on biologics in 2015.

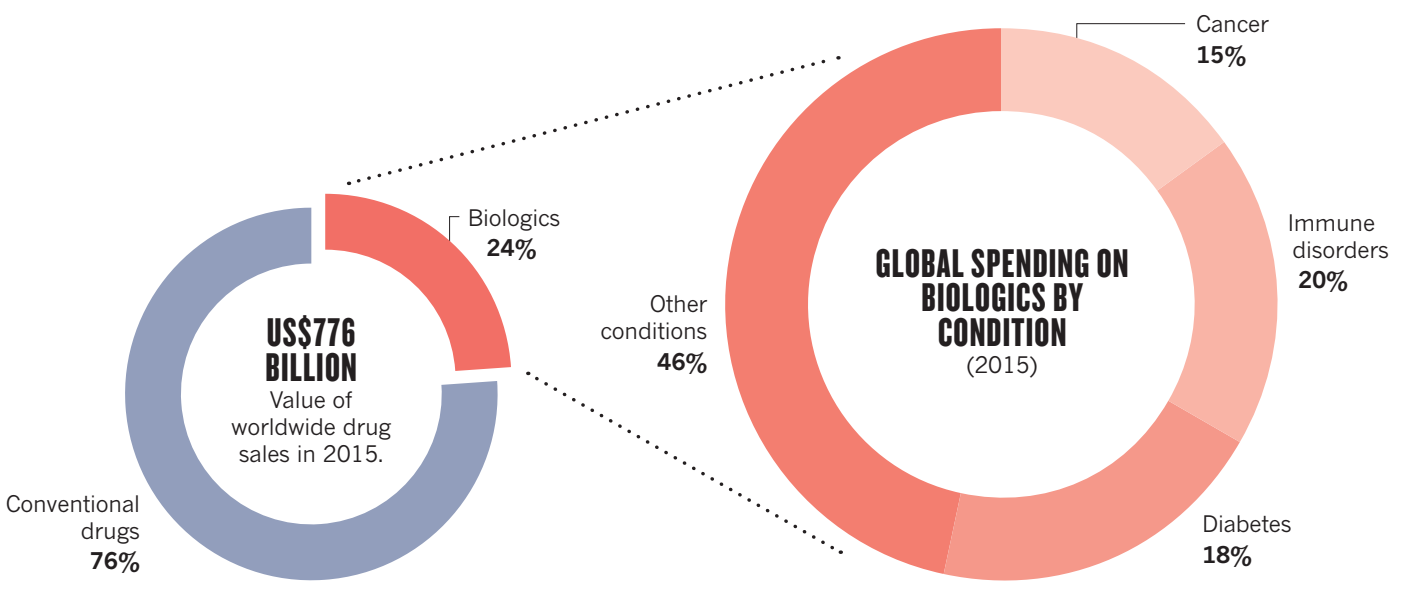

\section{A GROWING GLOBAL MARKET}

Biosimilars are copycat versions of biologics that have typically reached the end of their patent protection. The European Union established a regulatory framework for biosimilars in 2003, and Japan followed in 2009. The United States created a regulatory pathway in 2010 , but the first formally designated biosimilar hit the US market only in 2015. India set up formal guidelines for validating biosimilars in 2012, with refinement in 2016.

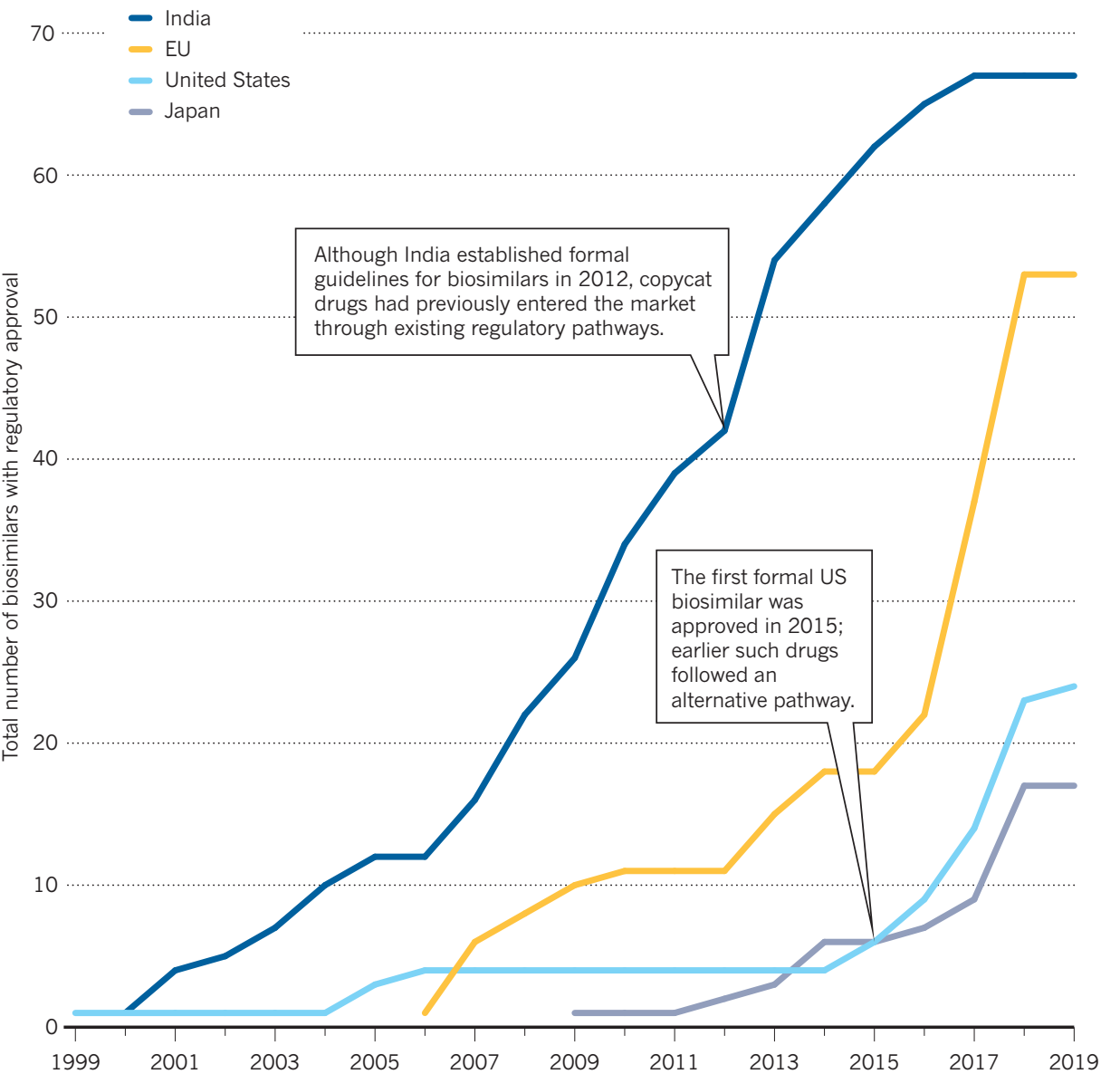

\section{SALES IMPACT}

Many biologics that would otherwise experience a steady or growing demand show a sharp loss of sales on the launch of their biosimilars.

- United States - EU

Avastin (bevacizumab; cancer)

Biosimilar Mvasi has been approved for EU and US markets, but has reached neither.

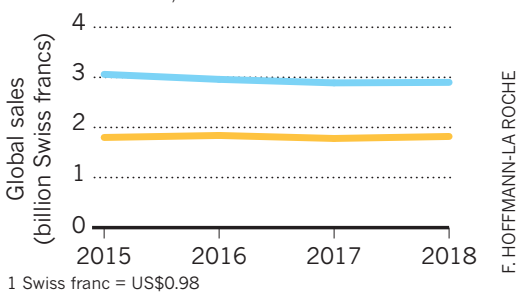

Herceptin (trastuzumab; cancer)

Biosimilar Ontruzant hit the EU in 2018; no Herceptin copy is sold in the US market.

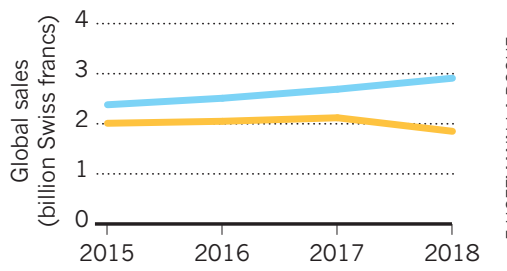

Remicade (infliximab; immune disorders) Several biosimilars went on sale in the EU in 2015 and in the United States in 2016.

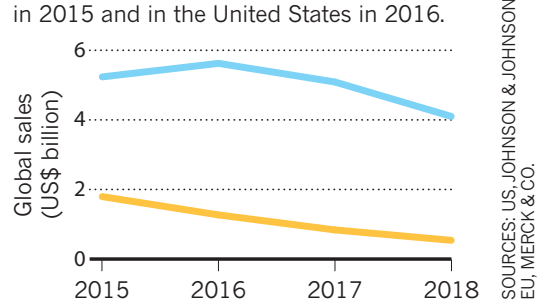




\section{BLOCKBUSTERS ON THE BRINK}

Time is running out for the manufacturers of some of the most lucrative biologics, with patents expiring in crucial markets over the next five years. Biosimilar developers are prepared, with pre-approved drugs ready to launch when these markets open. Notably, some biologics are covered by further patents related to their manufacture; these continue to offer protection after the original drug patent has expired.

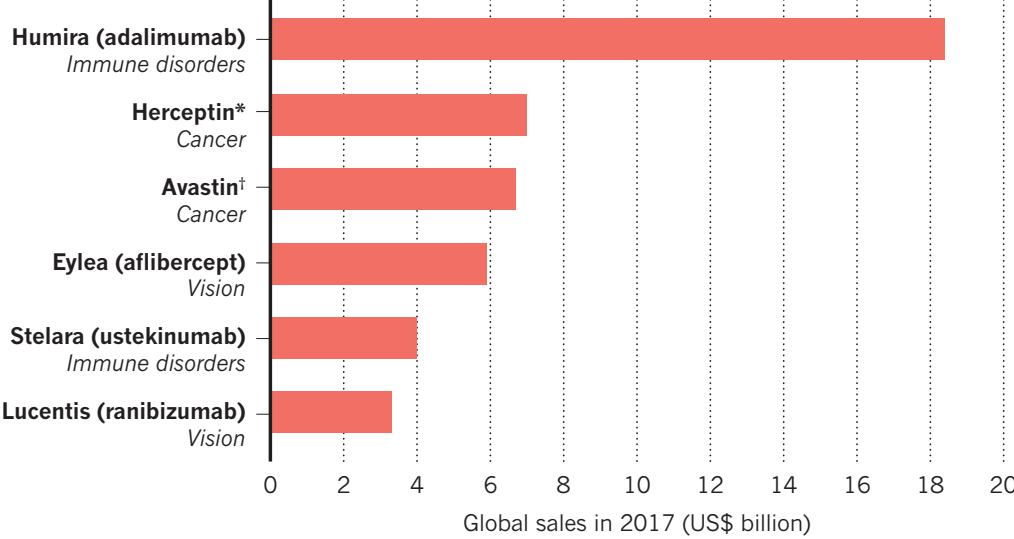

*Global sales originally posted in Swiss francs.

US sales originally posted in Swiss francs.

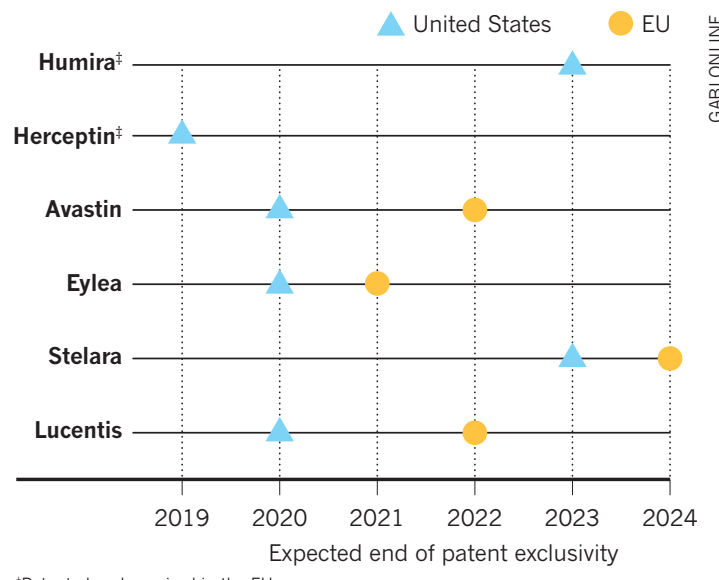

Patent already expired in the EU.

\section{ON TRACK FOR APPROVAL}

Biosimilars are more costly and difficult to produce than generic versions of small-molecule drugs. It can take 5-10 years and an investment of US $\$ 100$ million-250 million to bring a biosimilar to market, compared with about 2 years and $\$ 1$ million-10 million to develop a conventional generic - particularly in the complex patent landscape of the United States.

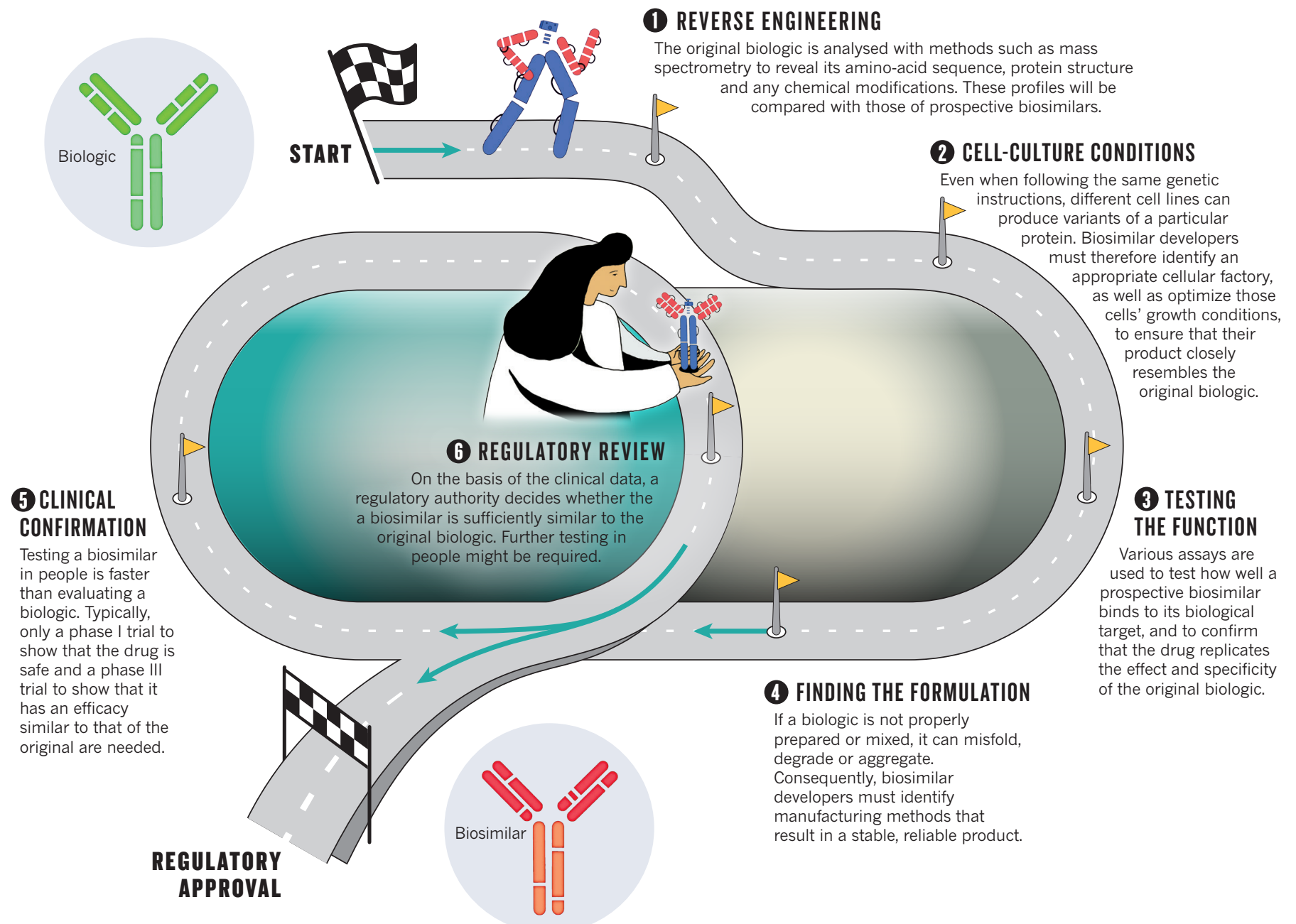

